\title{
Changes in the Histone Acetylation Patterns during the Development of the Nervous System
}

\author{
Bongki Cho, Hyun Jung Kim, Hyun Kim and Woong Sun* \\ Department of Anatomy, BK21 Program, Korea University College of Medicine, Seoul 136-705, Korea
}

\begin{abstract}
Epigenetic modification such as DNA methylation and histone acetylation plays essential roles in many aspects of cellular function and development of animals. There is an increasing amounts of evidence for dynamic changes in the histone acetylation of specific gene segments, but little attempt was made to examine global pattern changes in the histone acetylation in developing nervous system. In this study, we found that acetylated histone $\mathrm{H} 3$ and $\mathrm{H} 4$ immunoreactivities were relatively weak in neuroepithelial cells in the ventricular zone of developing rat cerebral cortex or chick spinal cord, compared to the immature young neurons in the cortical plate of a rat embryo or lateral motor column in chick spinal cord. On the other hand, adult neural stem cells in the dentate gyrus (DG) of rat hippocampal formation did not exhibit such diminished histone acetylation, compared to neuroblasts and mature DG neurons. These results suggest that the level of histone acetylation is highly dynamic and tightly linked to the neuronal types and the differentiation stages.
\end{abstract}

Key words: histone acetylation, nervous system, development, neuroepithelium

\section{INTRODUCTION}

Many biological processes are not only determined by DNA code itself, but also regulated by activity-related chromosomal remodeling (Clapier and Cairns, 2009). Since acetylation of histone modifies the basicity of histone protein which affects histone-DNA association, histone acetylation is essential event for the epigenetic control of gene expression (Allfrey et al., 1964; Hebbes et al., 1988; Riccio, 2010). The amount of histone acetylation is controlled by histone acetyltranferases (HATs) (Brownell et al., 1996) and histone deacetylases (HDACs) (Ruiz-Carrillo et al., 1975; Annunziato and Seale, 1983). During the development, changes in the histone acetylation greatly affect the differentiation of stem cells (Lee et al.,

Received April 19, 2011, Accepted May 9, 2011

* To whom correspondence should be addressed. TEL: 82-2-920-6404, FAX: 82-2-929-5696 e-mail:woongsun@korea.ac.kr
2004), neuronal maturation (Hsieh et al., 2004), and programmed cell death (Pelzel et al., 2010) via modulation of specific gene expressions which are responsible for these biological processes. It is believed that gene transcription machineries recruit histone modification enzymes into their transcriptome complex, and in this way specific gene transcription-mediated biological processes would be promoted. For instance, histone acetylation level declines during the differentiation of embryonic stem cells, which affects the gene transcription of stemness genes, such as Oct4 and Brachyury (Lee et al., 2004). Therefore, treatments of HDAC inhibitors, such as trichostatin A (TSA) and valproic acid (VPA), or deficiency of HDAC greatly affect many aspects of brain function, including differentiation of neurons and oligodendrocytes (Marin-Husstege et al., 2002; Hsieh et al., 2004), neuronal apoptosis (Pelzel et al., 2010), motor innervation (Mejat et al., 2005), and memory consolidation (Korzus et al., 2004).

While there have been extensive investigations of the histone acetylation patterns of specific gene promoter regions, little
Copyright (c) Experimental Neurobiology 2011. www.enjournal.org
This is an Open Access article distributed under the terms of the Creative Commons Attribution Non-Commercial License (http://creativecommons.org/licenses/by-nc/3.0) which permits unrestricted non-commercial use, distribution, and reproduction in any medium, provided the original work is properly cited. 
attempt was made to explore global changes in the histone acetylation during the normal embryonic development. In this study, we found that histone $\mathrm{H} 3$ and $\mathrm{H} 4$ acetylation levels were stronger in the early differentiating neurons in the rat cortex and chick spinal cord, comparing to the proliferating neuroepithelial cells in the ventricular zone. These results suggest that transient enhancement of histone acetylation may be an important event for neuronal differentiation.

\section{MATERIALS AND METHODS}

\section{Animals}

Time-pregnant C57Bl/6 mice were obtained from Orient Co. (Korea), and fertilized eggs were obtained from Pulmuone (Korea). Eggs were incubated in humidified incubator at $38^{\circ} \mathrm{C}$ for 3 days. Stage of chick embryo was identified according to the Hamilton-Hamburger's criteria (Hamburger and Hamilton, 1992). All experiments were carried out in accordance with the ethical guidelines of Korea University, and with the approval of the Animal Care and Use Committee of Korea University.

\section{Immunohistochemistry}

Immunohistochemical analyses were performed as previously reported (Sun et al., 2003). Briefly, brain or trunk tissues were isolated from embryos and fixed with $4 \%$ paraformaldehyde overnight. Tissues were then cryoprotected in 30\% sucrose, sectioned ( $20 \mu \mathrm{m})$ and attached on a gelatin-coated slide glass. Acetylated Histone
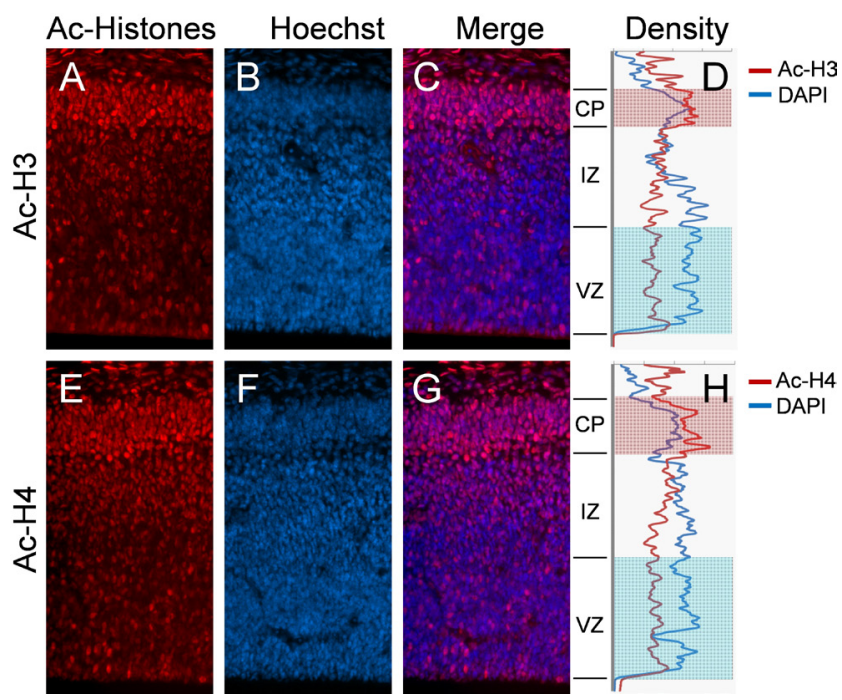

Fig. 1. Acetylation of histone $\mathrm{H} 3(\mathrm{~A} \sim \mathrm{D})$ and $\mathrm{H} 4(\mathrm{E} \sim \mathrm{H})$ in E17 mouse cerebral cortex. Acetylated Histones were labeled with red (A, E), and nuclei were labeled with blue (B, F). Merged images were shown in $\mathrm{C}$ and G. Densities of each signal were measured by ImageJ (NIH), and shown in D and H. VZ: ventricular zone, IZ: intermediate zone, CP: cortical plate.
H3 (Upstate, \#06- 599, 1 : 500) and H4 (Upstate, \#06-866, 1 : 1,000) antibodies were applied overnight. After several washes with PBS, secondary antibodies were applied for 30 minutes. Subsequently, sections were washed, counter-stained with Hechest33342, mounted and observed with a fluorescence microscope (Zeiss LSM510, Goettingen, Germany).

\section{RESULTS}

\section{Acetylation of histone $\mathrm{H3}$ and $\mathrm{H} 4$ in developing rat cerebral cortex}

Embryonic rat cerebral cortex (E17) was immunolabeled with antiacetylated histone $\mathrm{H} 3$ or $\mathrm{H} 4$ antibodies (Fig. 1). Interestingly, both acetylated histone $\mathrm{H} 3$ and $\mathrm{H} 4$ immunoreactivities were strong in the cortical plate (CP) where post-mitotic neurons localize, compared to the ventricular zone (VZ) and intermediate zone (IZ) enriched for mitotic/migrating neuroblasts. The concentration of histone proteins was proportional to the total DNA density, which may be affected by the size of nuclei. Therefore, we counterstained the nuclei DNA by Hoechst33342, and the relative densities of acetylated histones and DNA were measured. This analysis further confirmed the preferential histone acetylation in the CP.

\section{Acetylation of histone $\mathrm{H3}$ and $\mathrm{H} 4$ in developing chick spinal cord}

To determine whether similar difference in histone acetylation levels in developing nervous system in other species appear, we also examined the developing chick (E7) spinal cord (Fig. 2). Similar to the rat cerebral cortex, the level of histone acetylations were strong in the lateral motor column (LMC) where postmitotic motor neurons localize, whereas histone acetylation
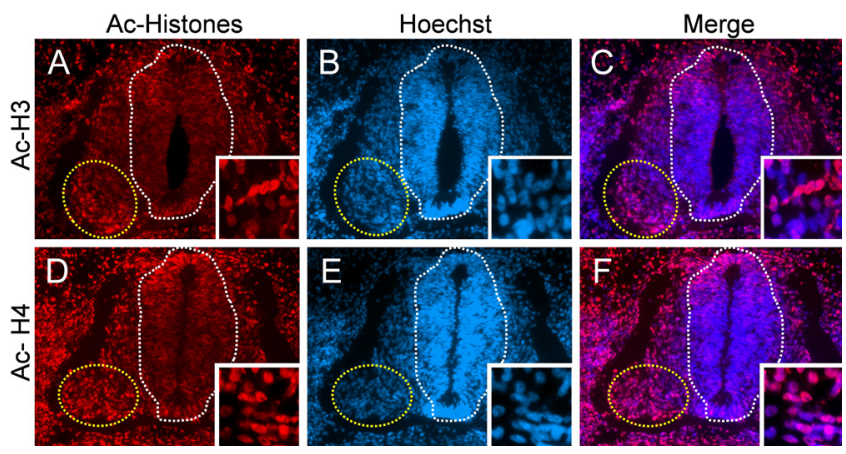

Fig. 2. Acetylation of histone $\mathrm{H} 3(\mathrm{~A} \sim \mathrm{C})$ and $\mathrm{H} 4(\mathrm{D} \sim \mathrm{F})$ in E7 chick spinal cord. Acetylated Histones were labeled with red (A, D), and nuclei were labeled with blue (B, E). Merged images were shown in C and F. White lines mark proliferating zone near the central canal, and yellow lines mark lateral motor column (LMC). Insets show large magnification view of LMC. 
were relatively weak in the periventricular regions enriched for proliferating neuroepithelial cells. Another important aspect of histone acetylation pattern is the heterogeneity within the same population. For instance, large magnification images of LMC clearly show that the intensities of acetylated histones were different among motor neurons.

\section{Acetylation of histone $\mathrm{H} 3$ and $\mathrm{H} 4$ in in adult mouse dentate gyrus}

These results suggest that histone acetylation is closely associated with the mitosis and differentiation of neural stem/progenitor cells. Neural stem cells remain in the specific areas of adult brain, and they continue to produce neurons. Therefore, we next examined whether adult neural stem cells and their progenitors also showed different levels of histone H3 acetylation (Fig. 3). To identify different cell types, three specific markers were used; glial fibrary acidic protein (GFAP), a marker for astrocytes and neural stem cells, doublecortin (DCX), a marker for neuroblasts, and neuronal nuclei (NeuN), a marker for differentiated neurons. Although a considerable heterogeneity of histone $\mathrm{H} 3$ acetylation levels was observed among the same cell populations, there was no significant difference among cell types.
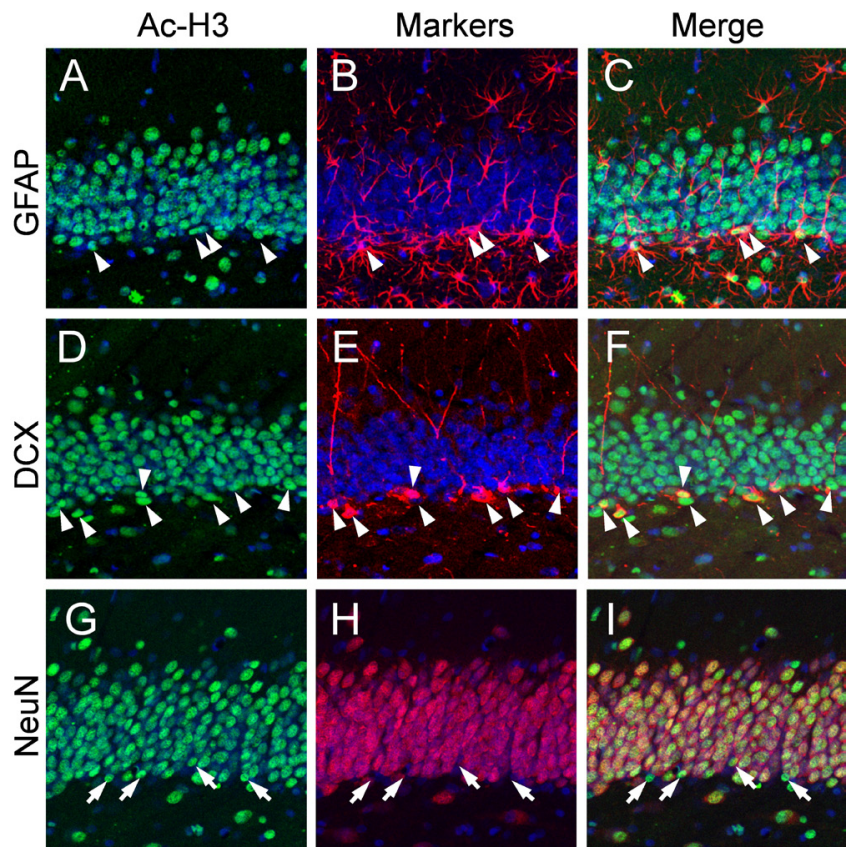

Fig. 3. Acetylation of histone $\mathrm{H} 3$ in adult mouse dentate gyrus. Markers for neural stem cells (GFAP, B), early neuroblasts (DCX, E), and mature neurons $(\mathrm{NeuN}, \mathrm{H})$ were co-labeled with acetylated histone H3 (A, D, G). Nuclei were counter- stained in blue with Hoechst33342. Merged images were shown in $\mathrm{C}, \mathrm{F}$, and I. Arrowheads in $\mathrm{A} \sim \mathrm{F}$ indicate double-labeled cells, and arrows in $\mathrm{G} \sim \mathrm{I}$ indicate NeuN-negative nuclei in the subgranular zone.

\section{DISCUSSION}

Increased acetylation of histones may promote the overall gene transcription efficiency. In this study, we found that developing neurons in the mouse cerebral cortex and chick spinal cord exhibit considerably high level of histone $\mathrm{H} 3$ and $\mathrm{H} 4$ acetylation, compared to the proliferating stem/progenitor populations. The level of histone acetylation was reported to increase during the postnatal development of rat brain (Serra et al., 1986), consistent with our current observation. Although there was little attempt to compare histone acetylation or RNA synthesis rates between stem cells and progenitor neurons, neurons appear to have higher histone acetylation level than glial cells (Hsieh et al., 2004; Shen et al., 2005; Humphrey et al., 2008). Considering that the size of neurons greatly expands during the differentiation, it appears that neurons have high demands for synthesis of many different RNA species during neuronal differentiation. However, it is noted that histone acetylation does not directly indicate the rate of RNA synthesis., Histone acetylation do not control the RNA polymerase activity, but it allows RNA polymerases to bind to the DNA. In this respect, increased histone acetylation may be linked to other biological processes.

In contrast to our in vivo data, it has been reported that cultured neural stem cells in vitro exhibit high level of global histone acetylation compared to their progenitor neurons or glial cells (Hsieh et al., 2004; Shen et al., 2005; Humphrey et al., 2008). Although it is unclear why these in vitro results are opposite to our current in vivo observations, it is important to note that epigenetic modification mainly depends on the extracellular signals, rather than cell autonomous events (Turner, 2009; Riccio, 2010). In this respect, it is no wonder that in vitro situation and in vivo environment resulted in different histone acetylation profiles. Considering that histone acetylation allows the "active" status of stem cells, and thus many stemness gene promoter regions are less acetylated, it does not mean that the global histone acetylation level should be high in less differentiated stem/progenitor cells.

Another important aspects about global histone acetylation levels identified in this study, is the heterogeneity among the same cell population. For instance, we found that only a subset of LMC chick motoneurons exhibited very strong level of histone acetylation. We failed to correlate the levels with known MN subtypes (data not shown), suggesting that these are differences among the same type of cells. This heterogeneity may be caused by highly dynamic nature of histone acetylation. In fact, histone acetylation is mainly regulated by two enzyme systems, histone acetyltransferases (HAT) and histone deacetylases (HDAC) (Riccio, 2010). Since these enzyme activities are dynamically 
regulated by multiple mechanisms, it is believed that the level of histone acetylation in cells are flexible and modulated by multiple factors, which may produce the diversity of histone acetylation even in the same population of cells.

In contrast to the developmental nervous system, we failed to detect any significant difference in the global histone acetylation levels among neural stem cells, neuroblasts, and mature neurons in the adult dentate gyrus. Compared to the embryonic development, neural stem cells and their progenitor neurons are similar in size and space, thus they may experience less dramatic changes in cellautonomous gene transcription and extracellular environment. Additional studies would clarify how these differences occur, and the mechanism/significance underlying it.

\section{ACKNOWLEDGEMENTS}

This work supported by grant from the Korean Ministry of Education, Science, and Technology via Brain Research Center of the 21st century Frontier Program in Neuroscience (2010K000803).

\section{REFERENCES}

1. Allfrey VG, Faulkner R and Mirsky AE (1964) Acetylation and Methylation of Histones and Their Possible Role in the Regulation of Rna Synthesis. Proc Natl Acad Sci USA 51:786794.

2. Annunziato AT and Seale RL (1983) Histone deacetylation is required for the maturation of newly replicated chromatin. J Biol Chem 258:12675-12684.

3. Brownell JE, Zhou J, Ranalli T, Kobayashi R, Edmondson DG, Roth SY and Allis CD (1996) Tetrahymena histone acetyltransferase A: a homolog to yeast Gcn5p linking histone acetylation to gene activation. Cell 84:843-851.

4. Clapier CR and Cairns BR (2009) The biology of chromatin remodeling complexes. Annu Rev Biochem 78:273-304.

5. Hamburger V and Hamilton HL (1992) A series of normal stages in the development of the chick embryo. 1951. Dev Dyn 195:231-272.

6. Hebbes TR, Thorne AW and Crane-Robinson C (1988) A direct link between core histone acetylation and transcriptionally active chromatin. EMBO J 7:1395-1402.

7. Hsieh J, Nakashima K, Kuwabara T, Mejia E and Gage FH (2004) Histone deacetylase inhibition-mediated neuronal differentiation of multipotent adult neural progenitor cells. Proc Natl Acad Sci USA 101:16659-16664.
8. Humphrey GW, Wang YH, Hirai T, Padmanabhan R, Panchision DM, Newell LF, McKay RD and Howard BH (2008) Complementary roles for histone deacetylases 1, 2, and 3 in differentiation of pluripotent stem cells. Differentiation 76:348-356.

9. Korzus E, Rosenfeld MG and Mayford M (2004) CBP histone acetyltransferase activity is a critical component of memory consolidation. Neuron 42:961-972.

10. Lee JH, Hart SR and Skalnik DG (2004) Histone deacetylase activity is required for embryonic stem cell differentiation. Genesis 38:32-38.

11. Marin-Husstege M, Muggironi M, Liu A and CasacciaBonnefil P (2002) Histone deacetylase activity is necessary for oligodendrocyte lineage progression. J Neurosci 22:1033310345.

12. Mejat A, Ramond F, Bassel-Duby R, Khochbin S, Olson EN and Schaeffer L (2005) Histone deacetylase 9 couples neuronal activity to muscle chromatin acetylation and gene expression. Nat Neurosci 8:313-321.

13. Pelzel HR, Schlamp CL and Nickells RW (2010) Histone $\mathrm{H} 4$ deacetylation plays a critical role in early gene silencing during neuronal apoptosis. BMC Neurosci 11:62.

14. Riccio A (2010) Dynamic epigenetic regulation in neurons: enzymes, stimuli and signaling pathways. Nat Neurosci 13:1330-1337.

15. Ruiz-Carrillo A, Wangh LJ and Allfrey VG (1975) Processing of newly synthesized histone molecules. Science 190:117128.

16. Serra I, Avola R, Condorelli DF, Surrentino S, Renis M, Kamiyama M, Hashim GA and Giuffrida AM (1986) Acetylation and phosphorylation of histones and nonhistone chromosomal proteins in neuronal and glial nuclei purified from cerebral hemispheres of developing rat brain. J Neurochem 46:1881-1887.

17. Shen S, Li J and Casaccia-Bonnefil P (2005) Histone modifications affect timing of oligodendrocyte progenitor differentiation in the developing rat brain. J Cell Biol 169:577589.

18. Sun W, Gould TW, Vinsant S, Prevette D and Oppenheim RW (2003) Neuromuscular development after the prevention of naturally occurring neuronal death by Bax deletion. J Neurosci 23:7298-7310.

19. Turner BM (2009) Epigenetic responses to environmental change and their evolutionary implications. Philos Trans R Soc Lond B Biol Sci 364:3403-3418. 